\title{
Diffusion of Innovations: Patenting or Standardization
}

\author{
Iosif Aronov, Aleksandr Zazhigalkin
}

Research Institute for Certification

3/10 Electrichesky per., Moscow

Russian Federation

Corresponding author: aiz@gost.ru

(Received September 30, 2016; Accepted November 11, 2016)

\begin{abstract}
In this paper, the authors proposed provisions under which the standards are more preferable than patents. They are defined in duopoly model of Standard - Patent. The article shows that the observed criterion (criteria) of efficiency standards in comparison with patents is a small scatter of royalties specific to the assessment of the cost of the license. Based on this criterion, sectors of the economy in which the standard can be more effective than patent for user were identified.
\end{abstract}

Keywords- Standard, Patent, Diffusion of Innovation, Duopoly Model, Royalty.

\section{Introduction}

At present time it is acknowledged that the innovation model of business behavior is becoming predominant (Wessner et al., 2012). It predefines the relevance of research in regard of factors impacting on the competitive ability of innovative systems. One of these factors are the channels disseminating these innovations under which the aggregation of technical and organizational solutions will be implied as confirmed through relationships between the knowledge holder and potential users for further transmission in codified and (or) non-codified layouts (Rogers, 2003). Licenses (patents) and standards are the main channels for disseminating industrial innovations (Blind and Jungmittag, 2008).

Innovative process research framework naturally raises the question: is it possible to treat the standardization as by means of an efficient diffusion channel of innovations if compared with patenting. In view of the latter the question of the kind does not arise, as a patent, for companies, is the best tool for handling business aimed at obtaining exclusive rights for a new product or way, conquering a stable position in the market and additional profit due to a specific licensing activity (Galasso and Schankerman, 2015).

The quantitative analysis of channels' efficiency from the view point of their impact on macroeconomic indicators (GDP) was conducted in a number of research works (Aronov et al., 2014; Blind and Jungmittag, 2008; Miotti, 2009; Swann, 2010). The comparison of elasticity coefficients in relation to standards and patents specifying the degree of impact of the Funds of Standards/Patents on GDP, does not enable to make a firm conclusion about the efficiency of a given channel (Table 1).

As viewed from data analysis in Table 1, the importance of patents for Germany and France is of more value if compared with standards, and for Russia, it is reverse. 
International Journal of Mathematical, Engineering and Management Sciences

Vol. 2, No. 2, 64-73, 2017

https://dx.doi.org/10.33889/IJMEMS.2017.2.2-007

\begin{tabular}{|l|c|c|c|}
\hline Elasticity coefficients & $\begin{array}{l}\text { Russia, } \\
\mathbf{1 9 9 8}-\mathbf{2 0 1 2}\end{array}$ & $\begin{array}{l}\text { Germany, } \\
\mathbf{1 9 6 0}-\mathbf{2 0 0 5}\end{array}$ & $\begin{array}{l}\text { France, } \\
\mathbf{1 9 5 0}-\mathbf{2 0 0 7}\end{array}$ \\
\hline Elasticity as per standards & 0,41 & 0,18 & 0,12 \\
\hline Elasticity as per patents & 0,03 & 0,34 & 0,37 \\
\hline
\end{tabular}

Table 1. Elasticity coefficients in relation to standards and patents

Making comparison of innovations' disseminating channels it is important to note the behavior of market operators, dealing with innovations launch. Let us consider the behavioral model of the market participants from this view point.

\section{Task Assignment of Research}

Suppose, it is known that the dissemination of a specific innovative product may be handled by the patenting procedures and further license sale or through the development of a national standard for it. In other words, the market participant has a choice: obtain a license for this innovative product or a standard. However, it is being supposed that a purchaser makes use of a patent or a standard. If forgo from this assumption, then, as it will be stated below, the efficiency of a standard in capacity of innovation diffusion channel becomes evident.

Let us see, if a standard may be competitive in relation to a patent? Patent holder aims at maximizing his profit establishing a license price unlike with a situation when the information about the product is coded in a standard which value and dissemination process are incomparably less than a license price.

The aim of the present analysis is to compare, under these conditions, the efficiency of each innovation dissemination channel on the assumption of the "market capture" potential. In fact this task assignment reminds of the task for the model of complementary suppliers - monopolists within the duopoly model framework (Tirole, 1988; He et al., 2007).

Let us assume that the license purchaser:

(i) initially aimed for license purchase, and it is a high price only that may force him to purchase a standard instead of a patent. Herewith, it is supposed that the product considered is available in both the patent and the corresponding standard;

(ii) the patent owner tends to maximize his profit, establishing a patent (license) disposition price;

(iii) it is assumed, that each purchaser uses either patent or standard;

(iv) the license price is much higher than the price of a standard.

The last assumption iv) calls for an appropriate argument. To this end, it could be possible to compare the average price of an ordinary license and the average price of a standard (for example, international or national) for the analyzed products. The problem is that the information in regard for license prices is a commercial secret, and that is why the comparison of license/standard values may be conducted only for particular cases. 
International Journal of Mathematical, Engineering and Management Sciences

Vol. 2, No. 2, 64-73, 2017

https://dx.doi.org/10.33889/IJMEMS.2017.2.2-007

It should be noted that the information is open only in regard for license cost expressed in nominal units such as fixed rates (royalty) as a percentage of licensed products net realizable value, its prime cost, gross profit or on a per production unit basis.

Let us view two examples. In 1995, the company Interline Resources Corp. signed a licensing agreement with Gadgil Western Corp on its contaminated oil refining technology for Bahrain and Singapore (Parr, 2007). Gadgil Western agreed to pay Interline an initial installment (lumpsum payment) in the amount of US\$ $1 \mathrm{M}$ and make further royalty payments in the amount of $2 \mathrm{c}$ per refined gallon. At that, a throughput performance equaled to $82 \mathrm{M}$ of gallons per year (Bahrain) and $165 \mathrm{M}$ gallons per year (Singapore). Thus, the license price equaled to US\$ 5,94M in 1995 prices or US\$ 9,35M in 2015 prices (www. westegg.com/inflation/).

At the same time, according to ISO data (www.iso.org) one international standard in oil refining segment varies from 58 to $198 \mathrm{CHF}$ (Table 2) or from 59-202 US\$.

\begin{tabular}{|l|c|}
\hline ISO standards & Cost, CHF \\
\hline ISO 10426-1:2009 & 158 \\
\hline ISO 10426-2:2003 & 198 \\
\hline ISO 13879:1999 & 58 \\
\hline ISO 16165:2013 & 138 \\
\hline ISO 16446:2013 & 38 \\
\hline ISO 21070:2011 & 88 \\
\hline ISO 21072:2009 & 88 \\
\hline
\end{tabular}

Table 2. Selective data on oil refining international standard prices

Thus, the license price is 46 thousand times higher than a standard price.

The second example refers to the Russian Federation. In accord with CJSC KORMAKO information, the price of an ordinary license (in lumpsum form, i.e. single payment) as for corrosion rate monitoring service ranges from $400 \mathrm{~K}$ RUB to $1,750 \mathrm{M}$ RUB (http://cormaco.ru/assets/SCAN_20130411_154853267.pdf). Therewith, the national standard price (inter-state) in the area of anti-corrosion protection ranges from 770 RUB to 1084 RUB (Table 3).

Hence, for the case at issue, the average license price is 1440 times higher than the standard price. Thus, it is believed that, in fact the license price is much higher than a standard price.

\begin{tabular}{|l|c|}
\hline GOST standards & Cost, RUB. \\
\hline GOST 9.302 & 1084 \\
\hline GOST 9.304 & 701 \\
\hline GOST 9.308 & 893 \\
\hline GOST 9.311 & 701 \\
\hline GOST 9.409 & 893 \\
\hline GOST 9.502 & 1020 \\
\hline
\end{tabular}

Note. http://www.vniiki.ru/doc.aspx?control

Table 3. Selective data on corrosion control inter-state standard 
International Journal of Mathematical, Engineering and Management Sciences

Vol. 2, No. 2, 64-73, 2017

https://dx.doi.org/10.33889/IJMEMS.2017.2.2-007

\section{Notations}

The following notations have been through for the design duopoly model:

$C$ - license price;

$Q$ - market capacity;

$x_{1}(C)$ - number of license purchasers with $C$ price;

$x_{2}(C)$ - number of standards users with license $C$ price;

$d$ - fixed costs connected with a patent support;

$b, k, L$-coefficients, $b>0, k \geq 1, L>0$.

$>$ a preference symbol.

\section{Duopoly Model}

Let us consider that the market is divided between patent and standard purchasers. Moreover, assume that the demand function on the patent is linear with respect to $C$ :

$x_{1}(C)=Q-b \cdot C$

Then the market for a standard of the product at issue is equal to:

$x_{2}(C)=Q-x_{1}(C)=b \cdot C$

Under these conditions the profit $P$ of a patent owner is regulated by a license price:

$\left.P=C \cdot x_{1}(C)\right)-d=C(Q-b \cdot C)-d$

It is easy to see that function (3) with respect to $C$ reaches the maximum with $\mathrm{Cm}$ :

$C m=Q / 2 b$

Herewith, the maximum profit of a patent owner is equal to

$P_{m}=P(C m)=Q / 4 b-d$

Hence, with patent price $C m=Q / 2 b$, the demand will be

$x_{1}(C)=Q-b \cdot C=Q / 2$

In other words, the patent owner, even with the optimal policy of licenses sale (within this model frames), will not be able to capture more than a half of the potential market. It is evident that the market will be equally divided between a patent and a standard.

In a general case the elasticity of demand at value is not viewed as a linear function, as exemplified from the results of (Zelenyuk, 2013). For this reason let's consider a more complicated situation, when the dependency of patent demand at value is described by a nonlinear function:

$x_{1}(C)=b /\left(C^{k}+L\right)$ 
International Journal of Mathematical, Engineering and Management Sciences

Vol. 2, No. 2, 64-73, 2017

https://dx.doi.org/10.33889/IJMEMS.2017.2.2-007

At that the condition is fulfilled: with $C=0, b / L=Q$

Function (5) appears to be universal enough, specifying a general case of the patent demand dependency on the value. On Fig.1 there is a family of functions (5) for case $Q=1000, b=0,1$.

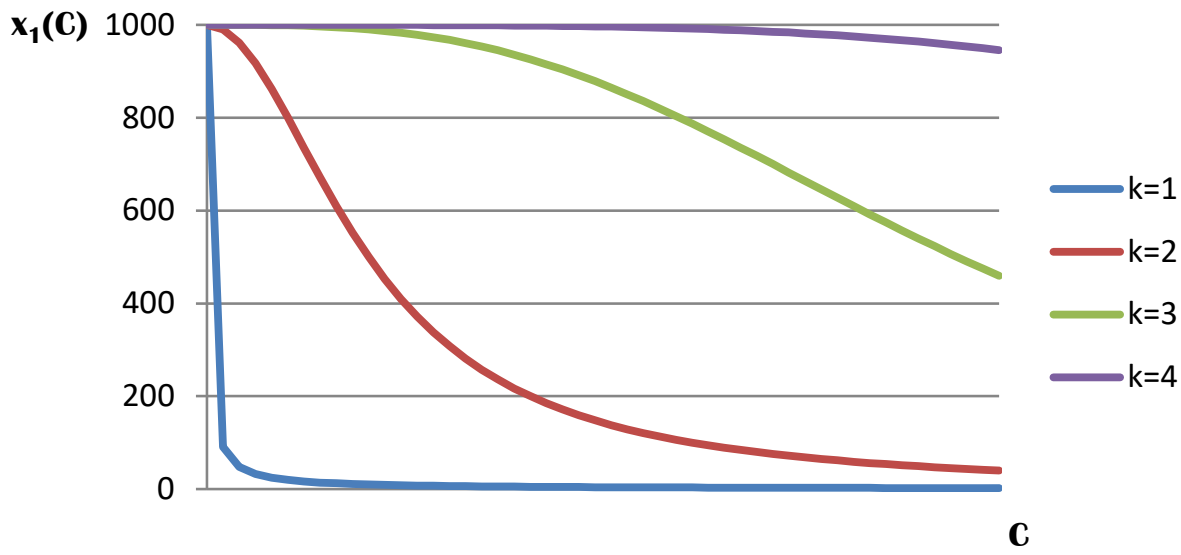

Fig. 1. Family of curves (5) for case $Q=1000, b=0,1$

It is evident from (5), where it follows that the profit of a patent owner with the license $C$ price will make:

$P=C \cdot x_{1}(C)-d=C \cdot b /\left(C^{k}+L\right)-d$

After simple computations, it follows that the maximum profit of a patent owner is provided in case of price:

$C m=(L /(k-1))^{1 / k}$

In this case the demand for patent will make

$x_{1}(C m)=(k-1) b / L k$

Then the market of a standard will be equal to

$x_{2}(C m)=Q-(k-1) b / L k=b / L-(k-1) b / L k=b / L k$

In a specific case when $k=2$, the market will be divided in halves between a patent and a standard and this is checked by a simple plugging of $k=2$ into equations (8) and (9).

In cases when $k>2$, the market will be reshaped in the favor of a patent (demand for license has no elasticity as for price), as in this situation the in equation

$x_{1}(\mathrm{Cm})>x_{2}(\mathrm{Cm})$ is correct. 
International Journal of Mathematical, Engineering and Management Sciences

Vol. 2, No. 2, 64-73, 2017

https://dx.doi.org/10.33889/IJMEMS.2017.2.2-007

In cases $1<k<2$ the market will be redeployed in favor of a standard (demand for license is elastic at value), as $x_{1}(\mathrm{Cm})<x_{2}(\mathrm{Cm})$.

Separate consideration is attributed to case $k=1$ as expressed by (5). It is easy to see that the optimal price for the patent owner in this situation does not exist. It is evident that with price $\mathrm{C}=$ $L$, the market will be equally divided between a patent and a standard, as it follows from the chain of equalities:

$x_{1}(C)=b /\left(C^{k}+L\right)=b /(C+L)=b / 2 L=Q / 2$.

In case if a patent price $C<L$, then the in equation is correct:

$x_{1}(C)>Q / 2$

In case the patent price $C>L$, then the in equation is correct:

$x_{1}(C)<Q / 2$

In equations (10) and (11) correspondingly mean, that with a patent price lower of a critical value $L$, it can "capture" over half of a potential market, and with a patent price greater of a critical value $L$, it comes the turn of a standard to "capture" over half of a potential market.

Abandoning the assumption $c$ ) with provision for correctness of condition $d$ ) leads to the conclusion that the standards is a far more efficient channel of innovations' disseminations (within the frames of this model), since its price is relatively low if compared with a license. That is why a party concerned practically always, together with a license, can obtain a standard (if available).

In fact, for the first time, patent/standard duopoly model is developed (in respect of a hypothetical innovative product), which demonstrates the standard's efficiency being a channel of disseminating new developments as more competitive if compared with a patent.

This conclusion fully corresponds to the results of research (Miotti, 2009) where, among others, the inquiry data of 1790 French companies are presented. It is noted that "in economically developed countries, such as France, where technological improvements are considered as main reasons for growth, the standardization process directly contributes to the widening of technological horizons, thus bringing benefits to the majority of people. Similar to patents, voluntary standards are viewed as one way to accumulate knowledge... and moreover, motivate for the knowledge dissemination".

\section{When a Standard is More Efficient than a Patent}

It would be tempting to try and select the product groups or economy sectors for which a standard, as innovations diffusion channel, is more valid than a patent.

To solve the task, let's make use of the factors, that:

(i) The standard is more efficient if compared with a patent in case of demand elasticity on license by the price, in view of what follows from the results of the previous item.

(ii) The license price is defined by the royalty, which value depends on the product type or economy sector. 
International Journal of Mathematical, Engineering and Management Sciences

Vol. 2, No. 2, 64-73, 2017

https://dx.doi.org/10.33889/IJMEMS.2017.2.2-007

In Table 4, the royalty values are presented as recommended for patents evaluation (Parr, 2007).

The analysis of this table shows that the royalty values for different economy sectors are widely dispersed and, for example, if for farm-machinery industry the royalty recommended value equals to 4,5 (no dispersion), then for the electronic industry 4-10\% dispersion is relevant. Each royalty dispersion values go along with the dispersion of demand values.

\begin{tabular}{|l|c|}
\hline Economy sector & Royalty recommended values, \% \\
\hline Air Industry & $6-10$ \\
\hline Automobile industry & $1-3$ \\
\hline Tool-making production facilities & $3-5$ \\
\hline Metallurgy industry & $5-8$ \\
\hline Manufacture of consumer durable goods & 5 \\
\hline Manufacture of mass consumption goods with short term usage & $0,2-1,5$ \\
\hline Farm-machinery industry & 4,5 \\
\hline Machine-building production & $4,7-7,5$ \\
\hline Machinery-producing industry & 4,5 \\
\hline Textile industry & $3-6$ \\
\hline Pharmaceutical industry & $2-5$ \\
\hline Chemical industry & $2-4$ \\
\hline Chemical machine-building & $4-7$ \\
\hline Electronic industry & $4-10$ \\
\hline Electro-technical industry & $1-5$ \\
\hline
\end{tabular}

Table 4. Recommended royalty values

To make further considerations more reasonable, let us be guided by the fact that the royalty count base in any case is similar, for example, as gross profit per year. It is evident that since the license price is fully defined by the royalty (lumpsum payment ignored), so instead of $C$ price one can talk about royalty $R, \%$. Next we assume that function (5) is known for each economy sector, and therewith this function is normalized to 1 . So to say, instead of function (5) the following function is considered:

$f(R)=b / Q\left(R^{k}+L\right)$,

which is equal to 1 with $R=0$.

In this case the general affirmation is reasonable that: for two monotonously fading functions $f_{1}(R)$ and $f_{2}(R)$, set on the mix of $R$, for which provisions are made:

$f_{1}\left(R_{1}=0\right)=f_{2}\left(R_{2}=0\right)=1$;

$\forall R_{0} \neq 0 \quad f_{1}\left(R_{0}\right)>f_{2}\left(R_{0}\right)$

from condition

$\Delta f_{1}\left(R_{1}\right)=\Delta f_{2}\left(R_{2}\right)$

it follows that

$\Delta R_{1}<\Delta R_{2}$. 
International Journal of Mathematical, Engineering and Management Sciences

Vol. 2, No. 2, 64-73, 2017

https://dx.doi.org/10.33889/IJMEMS.2017.2.2-007

Here $\Delta f_{1}(R), \Delta f_{2}(R)$ - are increments of functions $f_{1}(R)$ and $f_{2}(R)$ corresponding to royalty increments $\Delta R_{1}$ and $\Delta R_{2}$.

In other words, the same demand capacity for a more elastic function is ensured by less change of the price (royalty) in comparison with a less elastic demand function.

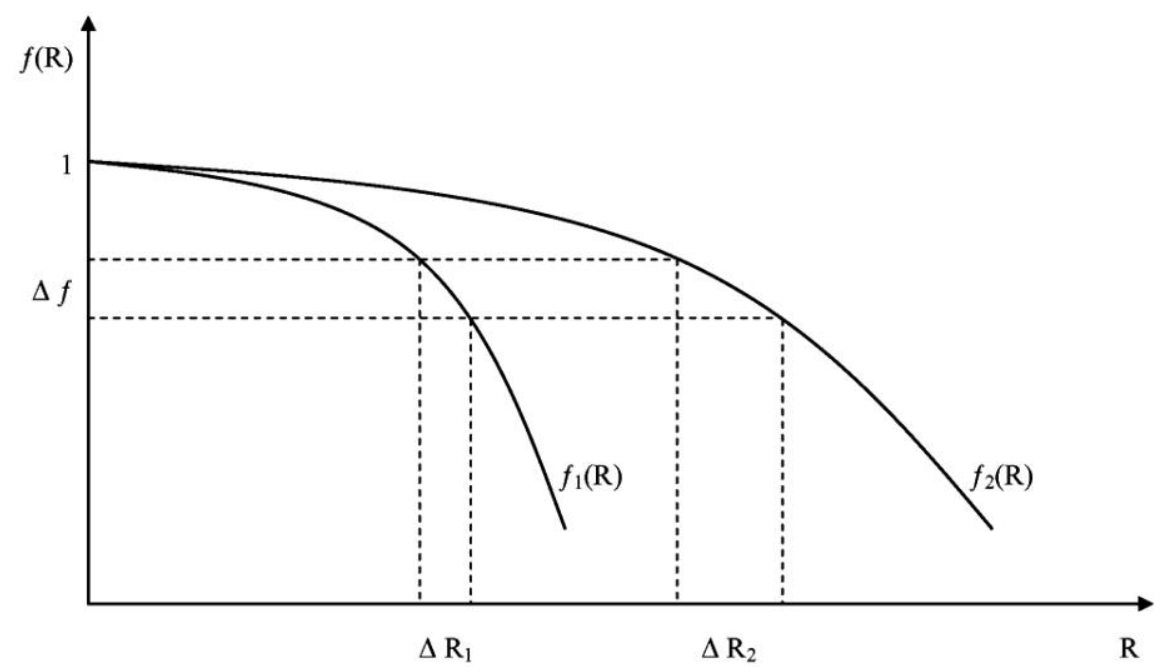

Fig. 2. Geometric proof of assertion

This assertion has enough transparency if geometrically realizable (Fig. 2).

As by condition, the monotonous function $f_{1}(R)$ is more elastic if compared with a monotonous function $f_{2}(R)$ then accordingly (Iljin et al, 2006):

$\left|f_{1}^{\prime}(R)\right|>\left|f_{2}^{\prime}(R)\right|$

Thus, as defined by the derivative of functions $f_{1}(R)$ and $f_{2}(R)$ from (14) it follows that:

$\left.\left|\Delta f_{1}(R) / \Delta R_{1}\right|>\mid \Delta f_{2}(R)\right) / \Delta R_{2} \mid$

Hence, to perform in equation (15) on condition of (12) it is necessary that

$\Delta R_{1}<\Delta R_{2}$

In so doing, the assertion is proved.

The inference of this assertion is presented by the fact, that more elastic functions of license demand are attributable to those economy sectors which are noted by far more elastic functions of license demand, and thus standard $(S)$ is more preferable than patent $(P)$, particularly in these economy sectors.

We specify this conclusion by the following:

$S>P$. 
International Journal of Mathematical, Engineering and Management Sciences

Vol. 2, No. 2, 64-73, 2017

https://dx.doi.org/10.33889/IJMEMS.2017.2.2-007

Reverse assertion is also correct: less elastic functions of license demand correspond to those economy sectors, which are noted for a wide dispersion of royalty values $\Delta R$, and it means that in these sectors the patent $(P)$ is more preferable than standard $(S)$. In other words, in this case $>$ $S$. These are the main results received in this article. In view of these conclusions, it is possible to draw again the Table 5 .

\begin{tabular}{|l|c|}
\hline Sector of economy & Royalty recommended values, \% \\
\hline Manufacture of consumer durable goods & 5 \\
\hline Manufacture of mass consumption goods with short term usage & $0,2-1,5$ \\
\hline Farm-machinery industry & 4,5 \\
\hline Machinery-producing industry & 4,5 \\
\hline Chemical industry & $2-4$ \\
\hline
\end{tabular}

Table 5. Royalty recommended values with distinguished economy sectors where $\boldsymbol{S}>\boldsymbol{P}$

\section{Conclusion}

Provisions with which the standards are more preferable than patents are defined in Standard/Patent Duopoly Model. The observable finding as for the standard efficiency if compared with the patent is the royalty moderate range of values, typical for patent (license) price evaluation. Sectors of the economy in which standards can be effective than patents were defined. In particular, manufacture of consumer durable goods, manufacture of mass consumption goods with short term usage, farm-machinery industry, machinery-producing industry and chemical industry can be attributed to such sectors.

\section{References}

Aronov, I. Z., Ilina, Ekatarina, V. \& Zazhigalkin, A. V. (2014). DIN Model Modification for the Assessment Economic Efficiency of Standardization. Communications in Dependability and Quality Management, an International Journal, 17(4), 27-33.

Blind, K., \& Jungmittag, A. (2008). The impact of patents and standards on macroeconomic growth: a panel approach covering four countries and 12 sectors. Journal of Productivity Analysis, 29(1), 51-60.

Galasso, A., \& Schankerman, M. (2015). Patents and cumulative innovation: Causal evidence from the courts. The Quarterly Journal of Economics, 130(1), 317-369.

He, X., Prasad, A., Sethi, S. P., \& Gutierrez, G. J. (2007). A survey of Stackelberg differential game models in supply and marketing channels. Journal of Systems Science and Systems Engineering, 16(4), 385-413.

Iljin, V. A., Sadovnichiy, V. A., \& Sendov, Bl. X. (2006). Mathematical analysis. M. Prospect.

Miotti H. (2009). The economic impact of standardization: Technological change, standards and long-term growth in France. Marketing and Innovation Department AFNOR Group, Paris.

Parr, R. L. (2007). Intellectual Property Valuation. The rate of royalty. Evaluation method of relief from royalty. Business Valuations Guide, 1.

Rogers, E. (2003). Diffusion of Innovations, 5th Edition. Free Press. A Division of Simon and Schuster.

Swann, G. M. Peter (2010, May). Report for UK Department of Business, Innovation and Skills (BIS), Version 2.2, (27).

The Inflation Calculator. www. westegg.com/inflation/.

Tirole, J. (1988). The Theory of Industrial Organization. MIT Press. 
International Journal of Mathematical, Engineering and Management Sciences

Vol. 2, No. 2, 64-73, 2017

https://dx.doi.org/10.33889/IJMEMS.2017.2.2-007

Wessner, C. W., \& Wolff, A. W. (2012). Rising to the Challenge: U.S. Innovation Policy for the Global Economy Committee on Comparative National Innovation Policies: Best Practice for the 21st Century. Board on Science, Technology, and Economic Policy and Global Affairs. The National Academies Press Washington DC.

Zelenyuk, V. (2013). A scale elasticity measure for directional distance function and its dual: Theory and DEA estimation. European Journal of Operational Research, 228(3), 592-600. 